\title{
How can we study common acute minor illness? Investigating recruitment and response rates in a prospective study on common colds in a general practice population
}

Gina Johnson, Lorraine Dakin South Bedfordshire Practitioners' Group, Wigmore Lane Health Centre, Luton, and Hilarie Bateman General Practice and Primary Care Research Unit, Cambridge University, Cambridge, UK

The objective was to explore the feasibility of prospective recruitment of general practice patients to a future trial on the effects of paracetamol on the symptoms of the common cold. In October 2000, recruitment letters were sent by a general practitioner to 276 patients aged between 18 and 75.65 patients returned signed consent forms. Postal packs were sent to the first 60 of these patients to reply. They contained a daily diary, symptom score questionnaires, an EQ-5D questionnaire, a pack of paracetamol tablets, and detailed instructions. When a cold developed and symptoms reached a specified level, one gram of paracetamol was taken four times daily for two days and questionnaires were completed for four days. Telephone interviews and crosschecking of data were used to identify difficulties in completing the study. The overall recruitment rate was $24 \%(65 / 276)$ with $95 \%$ confidence interval $19 \%$ to $29 \%$. Recruitment was significantly higher $(p<0.001)$ amongst patients registered with the main researcher $(43 \%(29 / 68))$ than with other doctors in the practice. The response rate, i.e., those who returned completed study packs, was $77 \%$ (46/60). Thirty participants experienced a cold and returned their data during the six months of the study, representing $50 \%(30 / 60,95 \% \mathrm{Cl} 37 \%$ to $63 \%)$ of participants and $11 \%(30 / 276,95 \% \mathrm{Cl}$ $7 \%$ to $15 \%$ ) of those initially approached. The mean cumulative four-day symptom score was 34.6, standard deviation 14.7. The EQ-5D health status on day four was 0.89 . We conclude that a prospective postal recruitment method in general practice is a potentially useful method of conducting research on the common cold. A better response is obtained when the initial letter is signed by the patient's own doctor.

Key words: common cold; general practice; methodology; paracetamol; subject recruitment

\section{Introduction}

There is an urgent need for more randomized controlled trials on common acute illness in primary care (Medical Research Council, 1997). Recent reviews of the literature (Bell-Syer and Klaber

\footnotetext{
Address for correspondence: Gina Johnson, South Bedfordshire Practitioners' Group, Wigmore Lane Health Centre, Luton LU2 8BG, UK. Email: gina.johnson@gp-E81075.nhs.net
}

Moffett, 2000; Peto et al., 1993; Ross et al., 1999) have identified major gaps in the information available on patient recruitment in this setting, and examined the factors relevant to involving general practitioners in research and maintaining their interest. However data on factors affecting the recruitment of patients into clinical trials on acute illness are very sparse.

In 1970, Howie and Clark completed a randomized controlled trial on the common cold in Glasgow, Scotland, using a prospective method. 
Amongst males aged 20 to 49 they recorded a 39\% recruitment rate to a randomized controlled trial, conducted entirely by post, on the use of an antibiotic (demethylchlortetracycline) in minor respiratory illness. They achieved a response rate of $92 \%$ for completing simple daily symptom diaries for six months.

A prospective study of upper respiratory tract infections in elderly people in Leicestershire, England in 1997, conducted by telephone with one home visit at the time of illness, achieved a $55 \%$ recruitment rate and a $79 \%$ response rate (Nicholson et al., 1997).

There is very little research to inform practice in the use of antipyretics in upper respiratory tract infection. A substantial body of evidence suggests that fever is a beneficial physiological response, and that the use of antipyretic medication may prolong illness (Kluger et al., 1996; Kramer et al., 1991). Paracetamol is very widely used in common cold 'remedies', but only one clinical trial on paracetamol and the common cold could be identified. A small number of student volunteers were artificially infected with rhinovirus, and the fifteen who were treated with paracetamol showed a statistically significant increase in nasal symptoms over those treated with placebo (Graham et al., 1990).

When researching the management of acute minor illness, there are obvious benefits in studying naturally-occurring diseases rather than those induced in the laboratory by innoculation with experimental viruses. However, it is difficult to design a study which permits the recruitment of subjects in the early stages of an acute illness. A prospective recruitment method has several advantages over the alternatives, as detailed in Table 1.

In the UK, each general practice has a relatively stable list of registered patients. This situation, which is unusual by international standards, provides a unique opportunity for research into acute illness. A prospective method of recruitment from such a list allows the sample to be drawn from a population whose characteristics are known, and which is not biased by age or sex or towards those who frequently attend the surgery. However, data on recruitment and response rates for such research in UK primary care are sparse.

This pilot study was, therefore, designed to test the methodology of prospective recruitment of general practice patients to a trial on the effects of
Table 1 Possible recruitment methods in common cold research

\begin{tabular}{|c|c|}
\hline Method & Problem \\
\hline $\begin{array}{l}\text { Poster in surgery } \\
\text { waiting room }\end{array}$ & $\begin{array}{l}\text { Bias towards frequent attenders } \\
\text { Encourages surgery visits for } \\
\text { colds }\end{array}$ \\
\hline $\begin{array}{l}\text { Recruitment in } \\
\text { community pharmacy }\end{array}$ & $\begin{array}{l}\text { Bias towards medication users } \\
\text { Slow and time-consuming }\end{array}$ \\
\hline $\begin{array}{l}\text { Customers buying } \\
\text { tissues in supermarkets }\end{array}$ & $\begin{array}{l}\text { Slow, untried method, unknown } \\
\text { study population }\end{array}$ \\
\hline Adverts on radio, buses & $\begin{array}{l}\text { Slow, untried method, unknown } \\
\text { study population }\end{array}$ \\
\hline University students & $\begin{array}{l}\text { Sample biased by age and IQ } \\
\text { Limited number of viruses in a } \\
\text { small community }\end{array}$ \\
\hline
\end{tabular}

paracetamol on the symptoms of the common cold. It aimed to measure:

- Recruitment rate;

- Response rate;

- Frequency of colds;

- Clarity of study instructions;

- Symptom scores;

- EQ-5D scores (a simple quality of life measure).

\section{Method}

Ethical approval was obtained from the South Bedfordshire Local Research Ethics Committee. We wanted to identify 60 patients who would be willing to undertake the pilot study. This number was chosen because it was small enough to be manageable but large enough to enable us to make a reasonable estimate of the mean and standard deviation of the symptom scores. As the response rate was unknown, we sent out the preliminary letters to invite interest in the study in batches. Those selected to receive the letter (adults between the ages of 18 and 75) were identified by random number selection from the general practice's AAH Meditel (Torex) computer system. A total of 276 letters, all signed by one doctor (GJ) were sent.

Ninety one $(33 \%)$ patients returned the pre-paid postcard expressing an interest and were sent the patient information sheet and consent form (stage one). Sixty-five $(24 \%)$ returned signed consent 
forms, of which the first 60 were entered into the study. Exclusion criteria for the study were: pregnancy; women of child-bearing age who were sexually active and not using a reliable method of contraception; renal disease; hepatic disease; paracetamol intolerance; lactose intolerance; regular users of analgesics containing paracetamol. Although the information about pregnancy and use of analgesics containing paracetamol was held on the computer system, the filters available were not sophisticated enough to exclude these patients. We therefore sent the exclusion list to the patients and allowed them to decide if they were eligible.

When the signed consent form was returned, a full trial pack was sent out by post (stage two). Time and close attention were committed to refining the design of the trial pack, trying out different versions on receptionists and relatives (who had no knowledge of our study) in order to prevent misunderstandings and avoid the inadvertent use of medical jargon. We were concerned that the pack might be put away and forgotten, so we included a fridge magnet in the hope that the daily diary would be prominently displayed in the patients' kitchens. We also included an example of how the diary should be completed.

Each study document was printed on a different coloured paper, in order to make the pack more visually appealing and to make the instructions easier to follow. Marketing research has shown that colour and a user-friendly format significantly improve mail survey response rates (LaGrace and Kuhn, 1995). Packs of paracetamol tablets were prepared by our local community pharmacist.

Participants were asked to complete a simple daily diary indicating the presence or absence of cold symptoms, until they developed a cold. As soon as the cold was established they were asked to take paracetamol tablets, one gram four times daily for two days, from the pack supplied. Prominent warnings were given to participants that they must avoid taking other products containing paracetamol during the trial. They were also asked not to take other 'cold remedies' or nonsteroidal anti-inflammatory drugs, even after the two days of paracetamol therapy.

On developing a cold (evidenced by a symptom score as validated by Jackson et al. (1968) of five or more), subjects were asked to complete a daily cold symptom score for four subsequent days. The symptoms measured were those relating to pain and fever (Group A - sore throat, headache and chilliness) and other symptoms (Group B runny nose, nasal stuffiness, sneezing, cough, and malaise). On the fourth day they were also asked to complete the EQ-5D questionnaire, a simple quality of life measure with questions about mobility, self-care, activity level, discomfort and anxiety or depression. The questionnaires and tablet packs were returned by post in a pre-paid envelope. Those who had not returned their packs after six months were contacted twice by telephone, partly to act as a reminder but also to identify whether any problems had been experienced. Semi-structured telephone interviews were conducted with five respondents after they had returned their packs. We felt that it would be inappropriate to interview the nonresponders. We were aware that this might create a concern amongst patients that their failure to participate in our research could be detrimental to the future medical care which they would receive from the practice.

\section{Results and problems}

Ours is a three-doctor practice, which has always maintained a strict personal list system. Because we know our patients so well, all of the doctors felt that they should check the lists of patients before the letters were sent out, to avoid approaching patients inappropriately. One patient selected at random by the computer was a young woman who at the time of the study was in the local hospital's Intensive Therapy Unit (she subsequently died). We decided that it would be unprofessional and distressing to send her a recruitment letter, although she did not satisfy any of the official exclusion criteria. In retrospect this vetting process should have been included in the original trial plan.

The inability to automatically exclude patients with contra-indications to the study from the mailing list was potentially damaging to the personal relationship between doctor and patient. We were concerned that patients might consider us incompetent in writing to invite them to take part in a study when we should know that, because of their medical history, they would not be eligible. However, manual checking of records was not feasible.

The overall recruitment rate was 24\% (65/276). 
Two sub-groups were analysed by age and sex for comparison with previous research, but neither was significantly different from the overall rate. Amongst men aged 20 to 49 the rate was $17 \%$ $(15 / 90)$, amongst patients aged 60 to 75 it was $23 \%(7 / 31)$. There was a noticeable difference in the recruitment rate of patients registered with different doctors (Table 2).

The average age of the sample was 45 years; $52 \%$ were women.

Of the 27 patients who completed the EQ-5D questionnaire, $11 \%$ were smokers (compared to a practice prevalence of $25 \%$ in this age group) and $48 \%$ were educated to degree level or had a professional qualification.

The mean number of times that these patients had attended the surgery in the twelve months before the study was 2.6 (range 0 to 11 ). We do not have data for the mean attendance rate for all patients of our practice, but in Sheffield in 1998 the mean annual attendance rate at a general practice was 3.4 (Waller et al., 2000). Twelve out of $59(20 \%)$ of our subjects had not attended the surgery at all in the preceding twelve months, and there were no frequent attenders in the sample (defined as those who had attended twenty times or more in the previous year).

Thirty patients $(50 \%)$ returned completed data sheets. A further $16(27 \%)$ returned their study packs but did not experience colds. The overall response rate was therefore $77 \%$ (Figure 1).

The symptoms measured were:

\section{Group A - pain/fever}

sore throat, headache, and chilliness

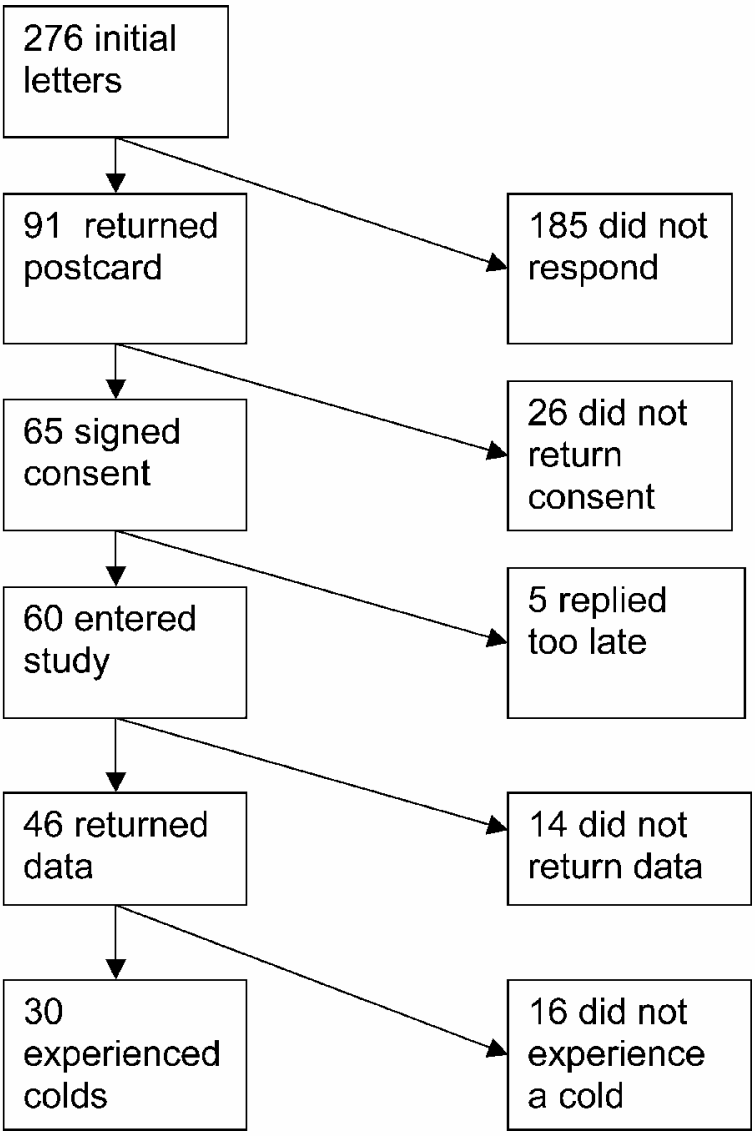

Figure 1 Study progress

\section{Group B - other}

runny nose, nasal stuffiness, sneezing, cough, and malaise.

Table 2 Recruitment rate of patients registered with different doctors

\begin{tabular}{lrrrrrrr}
\hline & \multicolumn{2}{c}{ Dr GJ } & \multicolumn{2}{c}{ Dr CE } & Dr IH-S & Total \\
\hline Practice population & 1954 & $32 \%$ & 2280 & $38 \%$ & 1827 & $30 \%$ & 6061 \\
Patients approached & 68 & $25 \%$ & 111 & $40 \%$ & 97 & $35 \%$ & 276 \\
Patients returning consent & 29 & $45 \%$ & 17 & $26 \%$ & 19 & $29 \%$ & 65 \\
Percentage of those approached & $43 \%$ & & $15 \%$ & & $20 \%$ & & $24 \%$ \\
\hline
\end{tabular}

The recruitment rate was significantly higher from patients of GJ than from other doctors $(p<0.001$, Pearson's chi-squared $=18.8,2$ degrees of freedom). 
The symptom scores and EQ-5D results are given in Table 3.

\section{Problems encountered by subjects}

Structured telephone interviews were held with five subjects, and no major problems were described. However, from the data returned it was clear that many patients $(61 \%, 14 / 23)$ had counted the first day on which the symptom score exceeded five as Day One for the purpose of completing the questionnaires, although the instructions stated that they should start them the following day. This would need clarification in any future study.

Most patients $(88 \%, 23 / 26)$ completed the daily diary, although two of the five interviewed said that they had filled it in on a weekly basis. Others only started it when they thought that they had a cold.

One patient did not complete the course of paracetamol, because he felt very ill after taking the first dose. Four other patients forgot to take some of the tablets (mean number forgotten, 4.2). No patient recorded taking other preparations containing paracetamol.

\section{Discussion}

\section{Generalizability of recruitment data}

This pilot study has provided useful information about the recruitment and drop-out rates of a prospective study of common colds, initiated from general practice. The generalisability of our findings may depend on several variables. In particular

Table 3 Symptom scores and EQ-5D status

\begin{tabular}{lccl}
\hline Symptom score & Mean & $\begin{array}{c}\text { Standard } \\
\text { deviation }\end{array}$ & $\begin{array}{c}\text { UK average } \\
\text { for age 45 }\end{array}$ \\
\hline Cumulative 4-day & 34.6 & 15 & \\
score & & & \\
Early (days 1 \& 2) & 20.1 & 7.7 & \\
Late (days 3 \& 4) & 14.5 & 10 & \\
Group A & 11.2 & 7.4 & 0.88 \\
Group B & 23.4 & 10.0 & \\
EQ5D health status & 0.89 & 0.13 & \\
on day 4 & & & \\
EQ thermometer & 75.5 & 13.7 & \\
score on day 4 & & & \\
\hline
\end{tabular}

our response rate was likely to have benefited from:

- Convenience (study materials completed by participants at time of own choice in own home);

- No invasive tests (no blood tests or swabs);

- Carefully-designed study pack (attractive and easy to use materials);

- Personal relationship between participant and researcher/GP.

In traditional UK general practice, patients develop a relationship with 'their' family doctor over many years. The existence of a personal list system within a practice, in which a patient sees the same doctor wherever possible, must strengthen this bond. Our data suggest that this relationship may be an important factor in the patient's decision whether to take part in a research project. In future studies of this nature we shall ensure that the patient's own doctor signs the initial contact letter.

The sample contained high proportions of nonsmokers and professionals, but the age-sex structure was similar to that of the practice population. Intuitively one might expect higher recruitment amongst elderly patients, who may have more time available for research studies, but this is not borne out by our data where the recruitment rate in this age group is not significantly different from that of the group as a whole. Howie and Clark (1970) found a recruitment rate of $39 \%$ amongst males aged 20 to 49. In our study the recruitment rate in this age-sex band was $17 \%$, which is not significantly different from the overall rate of $24 \%$.

\section{Real colds}

Previous studies on the common cold using symptom scores have been based on undergraduates with experimentally-induced colds, and have started measurements on the day of innoculation with a single virus. Graham et al. (1990) found that the mean cumulative symptom score over 14 days was 23.9, and Jackson et al. (1968) that the mean cumulative score over six days was 21.7. In Jackson's classic study, a cumulative (total) symptom score of 14 or more was the criterion for diagnosis of a cold; however nearly a quarter of his subjects did not achieve this level, but were included because they had a subjective impression of a cold.

The criterion used to confirm the diagnosis of a cold in this research (a daily score of five or 
above) had the effect of excluding less severe colds, but the four-day cumulative score of 34.6 still seems high in comparison with previous experiments. This may be related to the older age of the subjects, but it seems more likely that it represents a genuine difference between naturallyoccurring and experimental colds. Many different viruses have been identified in patients with colds, and the clinical picture is not homogeneous. The low infectivity of nasal innoculates also suggests that this may not be the normal method of transmission of the virus (Graham et al., 1990; Jackson et al., 1968). This suggests that research findings on the management of experimental colds may not be transferable to naturally-occurring colds. The EQ5D score did not prove to be a useful indicator in this setting.

The Medical Research Council has emphasized the need for more research on common acute illness in primary care (Medical Research Council, 1997). Our study has shown that prospective recruitment in UK general practice provides a useful methodology for such research, but we need to understand how best to manage the sampling and recruitment issues in this setting.

\section{Acknowledgements}

This study was supported by a grant from the Scientific Foundation Board of the Royal College of General Practitioners. The South Bedfordshire Practitioners' Group receives infrastructure funding from the Department of Health Eastern Region Research and Development Department. We are grateful to Professor John Howie for his support. Toby Prevost of CAMS kindly provided the statistical advice and analysis. Thanks also to Sheila McLaughlin, Ian Hill-Smith, Chris Ellis, and our practice staff, and also to all the patients who took part.

\section{References}

Bell-Syer, S.E.M. and Klaber Moffett, J.A. 2000: Recruiting patients to randomized trials in primary care: principles and case study. Family Practice 17(2), 187-91.

Graham, N.M.H., Burrell, C.J., Douglas, R.M., Debelle, P. and Davies, L. 1990: Adverse effects of aspirin, acetaminophen and ibuprofen on immune function, viral shedding, and clinical status in rhinovirus-infected volunteers. Journal of Infectious Diseases 162, 1277-82.

Howie, J.G.R. and Clark, G. 1970: Double-blind trial of early demethylchlortetracycline in minor respiratory illness in general practice. Lancet 1099-1102.

Jackson, G., Dowling, H., Spiesman I. and Boand, A. 1968: Transmission of the common cold to volunteers under controlled conditions. 1. The common cold as a disease entity. Annals of Internal Medicine 10, 267-78.

Kluger, M., Kozak, W., Conn, C., Leon L. and Soszynski, D. 1996: The adaptive value of fever. Infectious Disease Clinics of North America 10, 1-21.

Kramer, M., Naimark, L., Robert-Brauer, R., McDougall, A. and Leduc, D. 1991: Risks and benefits of paracetamol antipyresis in young children with fever of presumed viral origin. Lancet 337, 591-3.

LaGrace, R. and Kuhn, L.D. 1995: The effect of visual stimuli on mail survey response rates. Industrial Marketing Management 24, 11-18.

Medical Research Council. 1997: MRC Topic Review: Primary Health Care. London: Medical Research Council, p. 44.

Nicholson, K.G., Kent, J., Hammersley, V. and Cancio, E. 1997: Acute viral infections of upper respiratory tract in elderly people living in the community: comparative, prospective, population based study of disease burden. British Medical Journal 315, 1060-64.

Peto, V., Coulter, A. and Bond, A. 1993: Factors affecting general practitioners' recruitment of patients into a prospective study. Family Practice 10(2), 207-11.

Ross, S., Grant, A., Counsell, C., Gillespie, W., Russell, I. and Prescott, R. 1999: Barriers to participation in randomized controlled trials: a systematic review. Journal of Clinical Epidemiology 52(12) 1143-56.

Waller, J. and Hodgkin, P. 2000: General Practice: Demanding Work. Understanding patterns of work in primary care. Abingdon: Radcliffe Medical Press. 